\title{
Eficiência de escórias de siderurgia na cultura do feijoeiro em sistema de semeadura direta
}

\author{
Efficiency of steel slag in the common bean crop in the no-till system
}

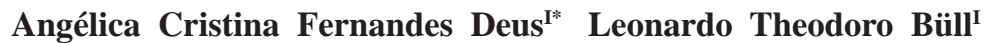

\section{RESUMO}

No sistema de semeadura direta (SSD), a prática da correção da acidez do solo se restringe ao uso do calcário, havendo poucas informações em relação às escórias de siderurgia. $O$ trabalho objetivou avaliar as alterações em propriedades químicas do solo, rendimento e absorção de nutrientes do feijoeiro, em função das formas de aplicação de escórias de siderurgia, comparadas ao calcário, na implantação do sistema de semeadura direta. O experimento foi conduzido na área experimental da Faculdade de Ciências Agronômicas de Botucatu (SP), no período de dezembro de 2010 a maio de 2011. Os tratamentos foram duas formas de aplicação de sete corretivos da acidez do solo: escórias de aciaria, de alto forno, de forno de panela, do aço inox (agrosilício), wollastonita, calcário dolomítico e calcário dolomítico calcinado, além de uma testemunha sem aplicação de corretivo. A dose aplicada de cada corretivo foi calculada para elevar a saturação por bases do solo a 70. A acidez do solo foi neutralizada até a camada de $20 \mathrm{~cm}$ com os calcários, enquanto a wollastonita e escória de forno de panela atingiram a camada de $10 \mathrm{~cm}$; para as escórias de aciaria, alto forno e o agrosilício, o efeito corretivo ficou restrito aos primeiros $5 \mathrm{~cm}$. O rendimento do feijoeiro aumentou com a aplicação de corretivos da acidez do solo, sem diferença entre o modo de aplicação.

Palavras-chave: Phaseolus vulgaris, silicatos, calagem.

\section{ABSTRACT}

In the no till system, soil acidity correction practice is restricted to limestone use and there is little information regarding slag. The study aimed to evaluate the amendments in soil chemical properties, yield and bean nutrient uptake according to the application forms of slags, compared to limestone, in the implantation of no till system. The experiment was conducted in the field at College of Agricultural Sciences, Botucatu (SP) from December 2010 to May2011. The treatments consisted of two application ways of seven soil acidity correctives: steel slag, blast furnace slag, ladle furnace slag, stainless steel slag(“agrosilício”), wollastonite, lime and calcined dolomite lime, plus one control without corrective application. Each material dose was calculated to raise the base saturation to $70 \%$. Soil acidity was neutralized down to $20 \mathrm{~cm}$ with limestones, whereas for wollastonite and ladle furnace slag those effects occurred down to $10 \mathrm{~cm}$, for steel slag, blast furnace slag and "agrosilício" the corrective effect was restricted to the first $5 \mathrm{~cm}$. The bean yield increased by application of correctives in soil acidity, without differences between the application ways.

Key words: Phaseolus vulgaris, silicates, liming.

\section{INTRODUÇÃO}

Com a adoção do sistema de semeadura direta (SSD), intensificou-se o interesse por alternativas para a correção da acidez do solo. Nesse sistema, o calcário, corretivo mais utilizado, é aplicado superficialmente sem incorporação, porém este apresenta baixa solubilidade em água e necessita entrar em contato com o solo para reagir. Assim, nesse sistema de manejo, a eficiência da calagem e a neutralização da acidez nas camadas mais profundas do solo podem diminuir, sendo os seus efeitos observados nas camadas mais superficiais do solo, como até os primeiros $10 \mathrm{~cm}$ (LEAL et al., 2008; CORRÊA et al.,2008, GONÇALVES et al., 2011). Apesar de os calcários serem poucos solúveis e os produtos de sua reação com o solo terem mobilidade limitada, há resultados experimentais que confirmam a eficiência da calagem superficial na correção da acidez de camadas superficiais e do subsolo em SSD (CAIRES et al., 2000; CAIRES et al., 2008).

IFaculdade de Ciências Agronômicas, Universidade Estadual Paulista “Júlio de Mesquita Filho”, Rua José Barbosa de Barros, 1780, Jardim Paraíso, 18610-307, Botucatu, SP, Brasil. E-mail: angeldeys@yahoo.com.br. *Autor para correspondência.

$$
\begin{array}{cc}
\text { Recebido 12.09.12 Aprovado 08.04.13 Devolvido pelo autor 22.07.13 } \\
\text { CR-2012-0837.R4 }
\end{array}
$$


Todavia, se, ao invés do calcário, forem utilizados os silicatos de cálcio e magnésio provenientes das escórias de siderurgia, os efeitos na correção da acidez do solo poderão ocorrer com maior rapidez. As escórias de siderurgia do ferro ou do aço são originárias do processamento em altas temperaturas, geralmente acima de $1400^{\circ} \mathrm{C}$, da reação do calcário com a sílica $\left(\mathrm{SiO}_{2}\right)$, presente no minério de ferro. As melhorias nas propriedades químicas do solo pela sua aplicação decorrem da ação neutralizante do $\mathrm{SiO}_{3}{ }^{2-}$, que reage com a água e libera íons $\mathrm{OH}^{-}$, neutralizando o $\mathrm{H}^{+}$e o $\mathrm{Al}^{3+}$ fitotóxico e, consequentemente, ocorre elevação do pH e dos teores de cálcio (Ca), magnésio (Mg) e saturação por bases (V\%), além da diminuição da concentração da acidez potencial (H+Al) (PRADO et al., 2001). Além disso, as escórias são fontes de silício (Si) e micronutrientes (PRADO et al., 2001) e disponibilizam P às plantas, porque os íons $\left(\mathrm{SiO}_{3}{ }^{2-}\right)$ saturam os sítios de adsorção pelo fosfato nos sesquióxidos de Fe e Al (PRADO \& FERNANDES, 2001).

Estudo conduzido por CORRÊA et al. (2009) evidenciou efeitos positivos de escória de aciaria aplicada superficialmente em SSD. A neutralização da acidez do solo após 27 meses de reação foi observada até a camada de $40 \mathrm{~cm}$ com a aplicação da escória, o que refletiu na maior produtividade da soja, enquanto o calcário proporcionou efeito corretivo até a camada de $20 \mathrm{~cm}$. Tal resultado pode ser atribuído aos compostos dissociáveis dos silicatos possuirem solubilidade quase sete vezes superior ao carbonato contido no calcário (ALCARDE, 1992), o que permite sua maior mobilidade no solo, associado ao fato de haver maior área superficial específica nos silicatos.

No entanto, o processo industrial promove a obtenção de vários tipos de escórias com recristalização diferente em função da quantidade de $\mathrm{Ca}, \mathrm{Mg}$ e do tempo de resfriamento, (PEREIRA et al., 2010). Essas características podem interferir na solubilidade dos seus compostos quando adicionado ao solo e, consequentemente, influenciar na reatividade do material. Assim, torna-se importante o estudo e o entendimento da reação dos diferentes tipos de escórias ao solo. Pouco se sabe sobre a utilização de silicatos de diferentes origens, composição, granulometrias (reatividade) em aplicações superficiais, tornando-se importante para o SSD conhecer as alterações no solo e na planta, para seu melhor aproveitamento, contribuindo também para redução do acúmulo de escórias geradas pelas indústrias siderúrgicas.

O presente trabalho objetivou avaliar as alterações em propriedades químicas do solo, rendimento e absorção de nutrientes do feijoeiro em função das formas de aplicação de escórias de siderurgia, comparadas ao calcário, na implantação do sistema de semeadura direta.

\section{MATERIAL E MÉTODOS}

O experimento foi instalado em condições de campo, na Fazenda Experimental Lageado, pertencente à Faculdade de Ciências Agronômicas da UNESP, Botucatu (SP), (latitude de $22^{\circ} 51^{\prime} 15^{\prime}$ ” S, longitude de $48^{\circ} 26^{\prime} 30^{\prime \prime}$ W e altitude de $740 \mathrm{~m}$ ). O trabalho foi desenvolvido em Latossolo Vermelho distrófico (EMBRAPA, 2006) e, na camada de 0 a $20 \mathrm{~cm}$, apresentava as características químicas: $\mathrm{pH}$ $\left(\mathrm{CaCl}_{2}\right)$ 4,2; M.O 32gdm ${ }^{-3}$; P resina $5 \mathrm{mg} \mathrm{dm}{ }^{-3} ; \mathrm{H}+\mathrm{Al}$, $\mathrm{K}$, Ca, Mg e CTC (mmolc $\mathrm{dm}^{-3}$ ) de 72;0,9; 10; 6; e 88, respectivamente, e V de 19\%. A área foi mantida com capim brachiaria sem manutenção por 20 anos.

O delineamento experimental foi de blocos ao acaso com parcela subdividida e quatro repetições. A parcela principal constituiu-se na forma de aplicação dos corretivos de acidez do solo, superficial e incorporado, enquanto as subparcelas, dos materiais corretivos, agrosilício (escória do aço inox) (AG), escória de aciaria (EA), escória de alto forno (EAF), escória de forno de panela (EFP), wollastonita (W), calcário dolomítico calcinado (CDC) e calcário dolomítico (CD), além de uma testemunha (T) sem aplicação de corretivo.

A caracterização química e física dos corretivos (Tabela 1) foi realizada de acordo com a legislação brasileira de calcários (BRASIL, 2006) e o Si total, determinado seguindo a metodologia proposta por KORNDORFER et al. (2004). A dose de cada corretivo foi calculada para elevar a saturação por bases do solo a 70\%, de acordo com RAIJ et al. (1996). A aplicação dos corretivos ocorreu em dezembro de 2010. Considerando a dose aplicada e o teor de silício total de cada material corretivo, verificou-se que a quantidade de silício fornecida com a aplicação dos materiais corretivos foi de 1,0 $\mathrm{Mg} \mathrm{ha}^{-1}$ com agrosilício; $1,3 \mathrm{Mg} \mathrm{ha}^{-1}$ com escória de aciaria; $5,2 \mathrm{Mg} \mathrm{ha}^{-1}$ com escória de alto forno; $1,6 \mathrm{Mg} \mathrm{ha}^{-1}$ com escória de forno de panela; $1,2 \mathrm{Mg} \mathrm{ha}^{-1}$ com wollastonita; $0,15 \mathrm{Mg} \mathrm{ha}^{-1}$ com calcário dolomítico e 0,66 Mg ha-1 com calcário dolomítico calcinado.

Em fevereiro de 2011, foi semeado o feijoeiro cultivar Pérola com espaçamento de 0,45m entre linhas e 14 sementes por metro linear. A adubação de semeadura foi calculada levando-se em consideração as características químicas do solo na camada de $0-20 \mathrm{~cm}$ e as recomendações de RAIJet al. 
Tabela 1- Caracterização química e física dos corretivos de acidez do solo.

\begin{tabular}{|c|c|c|c|c|c|c|c|c|c|}
\hline & $\mathrm{CaO}$ & $\mathrm{MgO}$ & ----------P & as $(\mathrm{ABI}$ & 2) ----------. & $\mathrm{RE}^{(3)}$ & $\mathrm{PN}^{(4)}$ & PRNT & $\mathrm{Si}$ \\
\hline \multirow{2}{*}{ Corretivos $^{(1)}$} & & & 10 & 20 & 50 & & & & \\
\hline & $\%$ & $\%$ & \multicolumn{3}{|c|}{------------\% partículas passantes----------- } & $\%$ & $\% \mathrm{ECaCO}_{3}$ & $\%$ & $\%$ \\
\hline AG & 37,65 & 9,55 & 91,4 & 77,7 & 53,5 & 71 & 84 & 60 & 13,6 \\
\hline EA & 28,13 & 6,10 & 99,9 & 80,0 & 47,9 & 71 & 70 & 50 & 14,2 \\
\hline EAF & 26,63 & 8,00 & 54,0 & 17,4 & 4,4 & 19 & 65 & 13 & 15,0 \\
\hline EFP & 36,10 & 5,76 & 99,6 & 97,4 & 52,9 & 80 & 77 & 62 & 21,6 \\
\hline $\mathrm{W}$ & 30,00 & 3,00 & 100,0 & 100,0 & 100,0 & 100 & 60 & 60 & 16,0 \\
\hline $\mathrm{CDC}$ & 38,39 & 23,63 & 100,0 & 99,9 & 95,9 & 98 & 120 & 119 & 3,9 \\
\hline CD & 27,75 & 16,40 & 99,7 & 86,9 & 58,1 & 75 & 88 & 67 & 9,7 \\
\hline Corretivos & $\mathrm{P}_{2} \mathrm{O}_{5}$ & $\mathrm{~K}_{2} \mathrm{O}$ & $\mathrm{Ca}$ & $\mathrm{Mg}$ & B & $\mathrm{Cu}$ & $\mathrm{Fe}$ & $\mathrm{Mn}$ & $\mathrm{Zn}$ \\
\hline AG & 3,5 & 0,3 & 256,0 & 16,1 & 0,3 & 0,02 & 38,0 & 5,3 & 0,05 \\
\hline EA & 11,0 & 0,3 & 216,3 & 15,6 & 0,9 & 0,03 & 193,5 & 21,5 & 0,07 \\
\hline EAF & 1,5 & 5,9 & 204,5 & 15,9 & 0,2 & 0,02 & 17,4 & 51,0 & 0,05 \\
\hline EFP & 2,5 & 0,3 & 274,0 & 15,6 & 0,3 & 0,02 & 28,6 & 3,7 & 0,05 \\
\hline $\mathrm{W}$ & 1,5 & 0,1 & 262,2 & 13,1 & 0,1 & 0,01 & 0,6 & 0,05 & 0,04 \\
\hline CDC & 2,5 & 0,8 & 244,0 & 16,6 & 0,1 & 0,05 & 2,3 & 0,1 & 0,09 \\
\hline CD & 3,5 & 0,2 & 275,0 & 16,0 & 0,4 & 0,02 & 36,8 & 4,8 & 0,05 \\
\hline
\end{tabular}

(1) agrosilício(AG), escória de aciaria (EA), escória de alto forno (EAF), escória forno de panela (EFP), wollastonita (W), calcário dolomítico calcinado (CDC) e calcário dolomítico (CD). ${ }^{(2)} \mathrm{ABNTn}^{\circ} 10=$ fração superior a 2,00mm; ABNT nํ20= fração de 2,00-0,84mm; ABNT nํ50= fração de 0,84-0,30mm; fundo (ABNT $\left.\mathrm{n}^{0}<50\right)=$ fração inferior a $0,3 \mathrm{~mm}$; ${ }^{(3)} \mathrm{RE}=$ reatividade, expressa o percentual do corretivo que reage em três meses; ${ }^{(4)} \mathrm{PN}=$ poder neutralizante, expressa o potencial químico do corretivo, em equivalente de $\mathrm{CaCO}_{3}$. $\left({ }^{* *}\right)$ Teores solúveis em Ácido Clorídrico $1+1$.

(1996) para a cultura do feijoeiro, e constou da aplicação de $250 \mathrm{~kg} \mathrm{ha}^{-1}$ da fórmula 08-28-16 ( $\left.\mathrm{N}-\mathrm{P}_{2} \mathrm{O}_{5}-\mathrm{K}_{2} \mathrm{O}\right)$ e $40 \mathrm{~kg} \mathrm{ha}^{-1}$ de Superfosfato triplo com $41 \%$ de $\mathrm{P}_{2} \mathrm{O}_{5}$. A adubação de cobertura realizada aos 27 dias após emergência das plântulas constou da aplicação de $90 \mathrm{~kg}$ ha $^{-1}$ de N, utilizando-se como fonte o sulfato de amônio.

Após 60 dias da aplicação dos tratamentos, foram coletadas amostras de solo nas camadas de 0-5, 5-10, 10-20 e 20-40cm para análise química, seguindo metodologia descrita por RAIJ et al. (2001), e $\mathrm{Si}$, utilizando extrator $\mathrm{CaCl}_{2}$, $01 \mathrm{~mol} \mathrm{~L}^{-1}$ de acordo com a metodologia descrita por KORNDORFER et al. (2004). Por ocasião do florescimento, coletouse amostra de folha para a análise dos teores totais de N, Ca e Mg, seguindo metodologia descrita por MALAVOLTA et al.(1997) e Si, de acordo com a metodologia descrita por KORNDORFER et al. (2004). No momento da colheita, 85 dias após a semeadura, avaliou-se o número de vagens por planta e rendimento. Os resultados foram submetidos à análise de variância e as médias comparadas pelo teste de Tukey $(\mathrm{P}<0,05)$.

\section{RESULTADOS E DISCUSSÃO}

$\mathrm{O}$ valor de $\mathrm{pH}$ do solo elevou-se com a aplicação dos corretivos de acidez, principalmente nas camadas de $0-5$ e $5-10 \mathrm{~cm}$, diminuindo o efeito corretivo em profundidade (Tabela 2). Na camada 5-10cm, os calcários EFP e W proporcionaram aumentos significativos nos valores de $\mathrm{pH}$, já na camada entre $10-20 \mathrm{~cm}$, apenas os calcários tornaram o pH mais elevado que o da testemunha. Não houve efeito significativo do modo de aplicação dos corretivos sobre a correção da acidez do solo.

A reação dos corretivos é muito afetada pelo grau de moagem do material, com partículas de menor tamanho reagindo rapidamente. Os corretivos EFP, CDC, CD e W possuíam granulometria mais fina do que as demais escórias, o que contribuiu para que os acréscimos nos valores de $\mathrm{pH}$ ocorressem com maior rapidez. A neutralização da acidez do solo na camada mais profunda $(40 \mathrm{~cm})$ não foi observada no período avaliado; embora os calcários W e EFP tenham apresentado resultados estatisticamente superiores ao da testemunha, os acréscimos nos valores de $\mathrm{pH}$ foram pequenos em comparação aos obtidos nas camadas mais superficiais, o que denota a dificuldade da neutralização da acidez do solo em maiores profundidades em curto prazo.

A EAF não promoveu incrementos nos valores de $\mathrm{pH}$, resultado semelhante foi obtido por PEREIRAet al.(2010); os autores avaliaram a reatividade de seis escórias de siderurgia, dentre elas duas escórias 
Tabela 2 - Valores de pH em $\mathrm{CaCl}_{2}, \mathrm{~V} \%$, Ca, Mg, P e Si no solo após 60 dias da aplicação incorporada e em superfície de agrosílicio (AG), escória de aciaria (EA), escória de alto forno (EAF), escória forno de panela (EFP), wollastonita (W), calcário dolomítico calcinado (CDC), calcário dolomítico (CD) e testemunha (T).

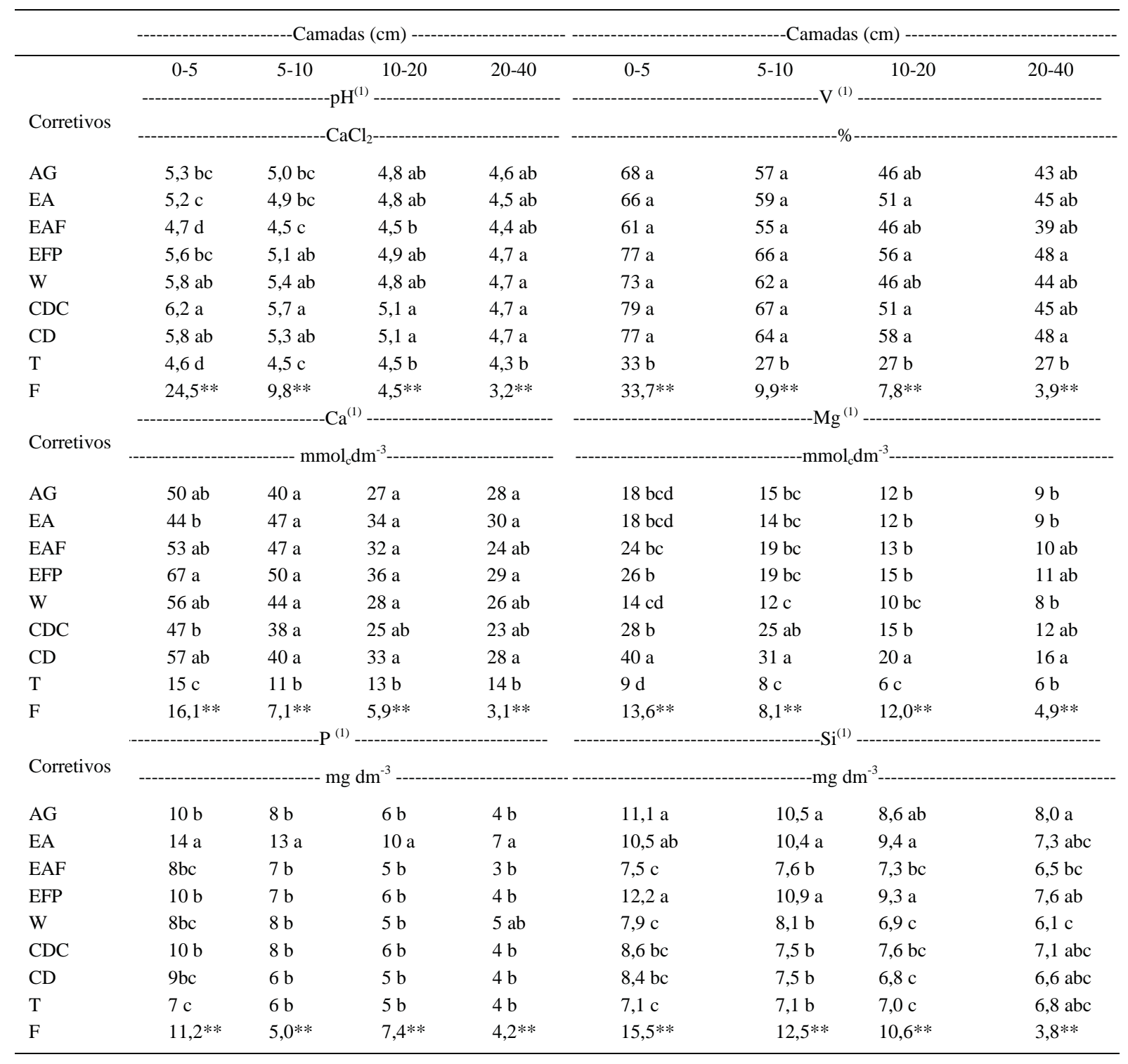

${ }^{(1)}$ Médias seguidas por letras distintas nas linhas diferem entre si, pelo teste Tukey em nível de $1 \%$ (**) de probabilidade. ns - não significativo.

de alto forno e uma de aciaria, e verificaram baixa eficiência na correção da acidez do solo e liberação de Ca e Mg pelas escórias de alto forno, atribuindo o resultado à baixa solubilidade do material.

O aumento da saturação por bases (V\%) foi observado em todas as camadas do solo, atingindo valores próximos e até mesmo superiores ao planejado de $70 \%$ nos primeiros $5 \mathrm{~cm}$. A razão da EAF ter proporcionado V\% próximo aos demais corretivos, sendo que esta possui baixo valor de
PRNT, pode ser atribuído à solubilização do cálcio e magnésio contidos nesse material durante o processo de extração na análise química, elevando o valor de $\mathrm{V} \%$ e tornando-o incompatível com o valor de $\mathrm{pH}$ atingido nesse tratamento.

O modo de aplicação dos corretivos aumentou o teor de P $\left(11 \mathrm{mg} \mathrm{dm}^{-3}\right)$ e Ca $\left(53 \mathrm{mmol}_{\mathrm{c}}\right.$ $\mathrm{dm}^{-3}$ ) do solo na camada de $0-5 \mathrm{~cm}$, quando realizada superficialmente. Para o Ca, esse resultado pode ser atribuído a não incorporação dos corretivos e, desta 
forma, a quantidade recomendada para a camada de $0-20 \mathrm{~cm}$ de solo ficou quase inteiramente depositada na superfície. Para o P, devido a sua baixa mobilidade no solo o acúmulo superficial, normalmente é mais acentuado do que dos demais nutrientes (RHEINHEIMER \&ANGHINONI, 2001). Na camada 5-10cm, o maior teor de Ca $\left(44 \mathrm{mmol}_{\mathrm{c}} \mathrm{dm}^{-3}\right)$ ocorreu com a aplicação incorporada, porque pode ter favorecido o contato corretivo com o solo, aumentando a sua dissolução.

Em todas as profundidades, a EA proporcionou maiores teores de $\mathrm{P}$, resultado semelhante foi relatado por CORRÊA et al. (2008). Tal fato explica-se pela competição dos ânions de silicatos contidos na escória com o P pelos mesmos sítios de adsorção, impedindo ou dificultando a adsorção de P (PRADO \& FERNANDES, 2001). Outra explicação é a liberação de P contido na EA; verifica-se que esse material possui $11,0 \mathrm{~g} \mathrm{~kg}^{-1}$ de $\mathrm{P}_{2} \mathrm{O}_{5}$ (Tabela 1), dessa forma, com a sua aplicação, foi fornecido $98,7 \mathrm{~kg} \mathrm{ha-1}$ de $\mathrm{P}_{2} \mathrm{O}_{5}$, o que pode ter contribuído em grande parte para o aumento de $\mathrm{P}$ no solo. Contudo, o aumento no teor de P do solo com a aplicação da EA não refletiu em aumento no tecido foliar; os corretivos não alteraram o teor de $\mathrm{P}$, que apresentou média de $14 \mathrm{~g} \mathrm{~kg}^{-1}$.

$\mathrm{O}$ incremento no teor de $\mathrm{Ca}$ com a aplicação dos corretivos foi observado em todas as camadas. Diferenças entre os materiais corretivos ocorreram apenas na camada de $0-5 \mathrm{~cm}$, com maior teor de Ca com a aplicação da EFP, possivelmente, pelo maior teor de Ca contido nesse material. Somente o CDC e CD foram capazes de alterar o teor de Mg na camadade $5-10 \mathrm{~cm}$ e apenas o CD proporcionou incremento em relação à testemunha na camada de $20-40 \mathrm{~cm}$.

Avaliando a composição química dos corretivos, verifica-se que os calcários apresentaram a maior percentagem de $\mathrm{MgO}$, o que justifica os resultados obtidos. Entre os calcários, o CDC possuía a maior percentagem de MgO, todavia, na camada de $0-5 \mathrm{~cm}$ e $10-20 \mathrm{~cm}$, o teor de $\mathrm{Mg}$ foi superior com o $\mathrm{CD}$; o menor teor de $\mathrm{Mg}$ no solo com o tratamento CDC é explicado pela absorção da planta (Tabela 3). Não houve diferença significativa no teor foliar de Mg entre os calcários, todavia, somente o CDC foi capaz de aumentar o Mg foliar em relação ao tratamento testemunha, evidenciado o processo de absorção.

$\mathrm{O}$ teor de $\mathrm{Si}$ no solo elevou-se com a aplicação do AG, EA e EFP em relação ao tratamento sem a correção da acidez, observando-se maior teor na camada de $0-5 \mathrm{~cm}$ (Tabela 2). A EAF foi aplicada em dose elevada, por ter baixo valor de PRNT e, com isso, a dose em Si também foi elevada, pelo fato de esse material possuir $15 \%$ de Si total. Contudo, não se observaram acréscimos significativos no teor de Si no solo. Dois pontos podem ser levantados a fim de explicar esse fato: um deles seria a forma como o material se apresentava (partículas grosseiras), que pode ter dificultado a solubilização do material e a liberação do elemento; outra explicação seria que o Si não estava na forma disponível. O teor de Si total em um material não significa que este estará na forma disponível, ele pode estar na forma amorfa com alto grau de organização, cuja liberação para a solução do solo é lenta.

Todavia, o Si apareceu no tecido vegetal do feijoeiro com a aplicação da EAF do mesmo modo

Tabela 3 - Teores médios de N, Mg e Si na parte aérea do feijoeiro, número de vagens por planta e rendimento de grãos em função da aplicação incorporada e em superfície de agrosilício (AG), escória de aciaria (EA), escória de alto forno (EAF), escória forno de panela (EFP), wollastonita (W), calcário dolomítico calcinado (CDC), calcário dolomítico (CD) e testemunha (T).

\begin{tabular}{|c|c|c|c|c|c|}
\hline Corretivos & $\mathrm{N}^{(1)}$ & $\begin{array}{l}\mathrm{Mg}^{(1)} \\
\mathrm{kg}^{-1}\end{array}$ & $\mathrm{Si}^{(1)}$ & № de vagens por planta ${ }^{(1)}$ & Rendimento $^{(1)} \mathrm{Mg} \mathrm{ha}^{-1}$ \\
\hline AG & $40 \mathrm{ab}$ & 4,4 bc & $5,2 \mathrm{ab}$ & $12,8 \mathrm{a}$ & $2,26 \mathrm{a}$ \\
\hline EA & $40 \mathrm{ab}$ & 4,3 bc & $6,2 \mathrm{a}$ & $11,9 a b$ & 2,66 a \\
\hline EAF & $38 a b$ & $4,1 \mathrm{c}$ & $6,4 \mathrm{a}$ & $10,0 \mathrm{~b}$ & $2,10 \mathrm{ab}$ \\
\hline EFP & $42 \mathrm{ab}$ & $5,1 \mathrm{ab}$ & $5,3 \mathrm{ab}$ & $11,2 \mathrm{ab}$ & 2,48 a \\
\hline W & $41 \mathrm{ab}$ & 4,3 bc & 6,6 a & $10,4 a b$ & $2,35 \mathrm{a}$ \\
\hline CDC & $42 \mathrm{a}$ & $5,4 \mathrm{a}$ & $4,2 \mathrm{ab}$ & $11,4 \mathrm{ab}$ & $2,06 \mathrm{ab}$ \\
\hline $\mathrm{CD}$ & $37 \mathrm{ab}$ & 4,8 abc & 3,5 b & $11,4 \mathrm{ab}$ & $2,42 \mathrm{a}$ \\
\hline $\mathrm{T}$ & $36 \mathrm{~b}$ & 4,2 bc & $4,6 a b$ & 9,4 b & $1,55 \mathrm{~b}$ \\
\hline $\mathrm{F}$ & $3,6^{* *}$ & $4,9 * *$ & $3,6^{* *}$ & $3,3^{* *}$ & $5,6^{\mathrm{ns}}$ \\
\hline
\end{tabular}

${ }^{(1)}$ Médias seguidas por letras distintas nas linhas diferem entre si, pelo teste Tukey em nível de $1 \%$ (**) de probabilidade. ${ }^{*}$ - não significativo. 
que ocorreu com a W (Tabela 3); a partir desses resultados, infere-se que a metodologia utilizada para a extração de silício disponível no solo possa não estar sendo adequada para expressar o Si disponível para a planta. Embora o extrator cloreto de cálcio 0,01mol $\mathrm{L}^{-1}$ mostre maiores correlações entre o Si extraído no solo e a quantidade de silício absorvida pela planta (PEREIRA et al.,2007), os resultados ainda não são satisfatórios. Em estudos com extratores de silício no solo, o $\mathrm{CaCl}_{2}$ tem apresentado estreita faixa de extração, (NARAYANASWAMY \& PRAKASH, 2010; RODRIGUES et al.,2003) e essa amplitude influencia na exatidão da análise, pois pode promover erros de análises (PEREIRA et al.,2007).

A aplicação da EFP, EA e AG forneceram 1,6; 1,3 e 1,0Mg de Si ha-1 ${ }^{-1}$, respectivamente. A diferença de aproximadamente 300 e $500 \mathrm{~kg} \mathrm{ha}^{-1} \mathrm{de} \mathrm{Si}$ a mais com a aplicação da EFP, em relação à EA e AG, não refletiu na diferenciação da disponibilidade de $\mathrm{Si}$ no solo. Resultados semelhantes foram relatados por PEREIRA et al.(2004) que, ao estudar 10 tipos de escórias de siderurgia, aplicadas na dose de $125 \mathrm{~kg}_{\text {de Si ha-1 }} \mathrm{em} \mathrm{um}^{-}$ Neossolo Quartzarênico Órtico, verificaram variação na disponibilidade de Si no solo e na absorção por plantas de arroz, evidenciando que os materiais possuem solubilidade variada. De acordo com KORNDORFER et al. (2003), as escórias de alto forno, normalmente, possuem maiores concentrações de $\mathrm{Si}$, todavia, com baixa solubilidade; as de aciaria possuem menores concentrações, porém, com maior solubilidade. Entre as escórias de aciaria, também há variação nos teores e solubilidade do Si e as escórias do aço inox são as que apresentam o Si na forma mais solúvel.

As diferenças resultantes da incorporação ou não dos corretivos para o feijoeiro somente se manifestaram na população final de plantas, sendo esta maior quando os corretivos foram incorporados (262.986 plantas ha-1). Provavelmente, a incorporação favoreceu a liberação dos nutrientes, o que beneficiou o número de plantas nesse tratamento. A aplicação dos corretivos aumentou o número de vagens por planta, todavia, apenas o AG teve aumento significativo em relação ao tratamento testemunha (Tabela 3). Para o rendimento de grãos, não houve diferença entre os corretivos utilizados e o fato da aplicação da EAF não ter atingido níveis adequados na correção da acidez do solo e apresentar rendimento de grãos semelhante aos demais corretivos pode ser atribuído aos teores adequados de N, Ca e Mg no tecido vegetal, bem como o Si.

A aplicação incorporada ou em superfície influenciou apenas no teor de Ca e Mg foliar. O aumento no teor de Ca no solo com a aplicação incorporada dos corretivos refletiu no aumento de Ca nas plantas, com $13 \mathrm{~g} \mathrm{~kg}^{-1}$ no tratamento, com incorporação dos corretivos diferindo significativamente do tratamento com aplicação superficial. Para o teor de Mg foliar, ocorreu o inverso, houve aumento significativo quando os corretivos não foram incorporados, com a média de $4,9 \mathrm{~g} \mathrm{~kg}^{-1}$.

\section{CONCLUSÃO}

A acidez do solo foi neutralizada até a camada de $20 \mathrm{~cm}$ com os calcários, enquanto a wollastonita e escória de forno de panela atingiram a camada de 10cm; para as escórias de aciaria, alto forno e o agrosilício, o efeito corretivo ficou restrito aos primeiros $5 \mathrm{~cm}$. O modo de aplicação dos corretivos na implantação do sistema de semeadura direta não alterou a neutralização da acidez do solo. O rendimento do feijoeiro aumentou com a aplicação de corretivos da acidez do solo, sem diferença entre o modo de aplicação.

\section{AGRADECIMENTO}

À Fundação de Amparo à pesquisa do Estado de São Paulo (FAPESP), pela bolsa de estudo ao primeiro autor e apoio financeiro ao projeto de pesquisa.

\section{REFERÊNCIAS}

ALCARDE, J.C. Corretivos da acidez do solo: características e interpretações técnicas. São Paulo: ANDA, 1992.62p. (Boletim Técnico 6).

BRASIL, Ministério da Agricultura. Secretaria Nacional de Defesa Agropecuária. Portaria n.35, de 04 de julho de 2006. Diário Oficial, Brasília, 12 de julho de 2006. Seção 1, p.32.

CAIRES, E.F.et al. Calagem na superfície em sistema plantio direto. Revista Brasileira de Ciência do Solo, v.24, p. 161-169, 2000. Disponível em: <http://sbcs.solos.ufv.br/solos/revistas/ v24n1a18.pdf>. Acessoem: 16 nov.2012.

CAIRES, E.F. et al. Soil acidity, liming and soybean performace under no-till. Scientia Agricola, v.65, n.5, p.532-540, 2008. Disponível em: <http://www.scielo.br/pdf/sa/v65n5/ a13v65n5.pdf>. Acesso em: 24 ago. 2012.doi: 10.1590/S010390162008000500013.

CORRÊA, J.C. et al. Aplicação superficial de diferentes fontes de corretivos no crescimento radicular e produtividade da aveia preta. Revista Brasileira de Ciência do Solo, v.32, p.1583-1590, 2008. Disponível em: <http://www.scielo.br/pdf/rbcs/v32n4/ a22v32n4.pdf>. Acesso em: 22 out.2010. doi: 10.1590/S010006832008000400022.

CORRÊA, J.C.et al. Aplicação superficial de calcário e diferentes resíduos em soja cultivada no sistema plantio direto. Bragantia, v.68, n.4, p.1059-1068, 2009. Disponível em: <http://www.scielo. br/pdf/brag/v68n4/v68n4a27.pdf>. Acesso em: 25 jun. 2011.doi: 10.1590/S0006 87052009000400027. 
EMBRAPA. Centro Nacional de Pesquisa de Solos. Sistema brasileiro de classificação de solos. Rio de Janeiro: EMBRAPA Solos, 2006. 306p.

GONÇALVES, J.R.P. et al. Granulometria e doses de calcário em diferentes sistemas de manejo. Acta Scientiarum Agronomy, v.33, n.2, p.369-375, 2011. Disponível em: <http://www.alice. cnptia.embrapa.br/bitstream/doc/898198/1/2011AP15.pdf>. Acesso em: 19 abr. 2011. doi: 10.4025/actasciagron.v33i2.3659.

KORNDÖRFER, G.H. et al. Silicatos de cálcio e magnésio na agricultura. Uberlândia: GPSi-ICIAG-UFU, 2003. 53p. (Boletim Técnico n.1). Disponível em: <http://www.ufmt.br/gemt/Diversos/ Textos\%20Diversos\%20e\%20Palestras/Textos\%20Tecnicos/ BoletimTecnicoSilicato.pdf>. Acesso em: 29 out. 2012.

KORNDÖRFER, G.H. et al. Análise de silício no solo, planta e fertilizante. Uberlândia: GPSi, 2004. 50p. (Boletim Técnico n.02).

LEAL, A.J.F. et al. Aplicação de calcário e culturas de cobertura na implantação do sistema plantio direto em cerrado. Revista Brasileira de Ciência do Solo, v.32, p.2771-2777, 2008. Disponível em: <http://www.scielo.br/pdf/rbcs/v32nspe/22.pdf>. Acessoem: 24 ago. 2012.doi: 10.1590/S0100-06832008000700022.

MALAVOLTA, E. et al. Avaliação do estado nutricional das plantas: princípios e aplicações. 2.ed. Piracicaba: Potafos, 1997.319p.

NARAYANASWAMY, C.; PRAKASH, N.B. Evaluation of selected extractants for plant-available silicon in rice soils of southern India. Communications in Soil Science and Plant Analysis, v.41, n.8, p.977-989, 2010. Disponível em: <http://www. tandfonline.com /doi/abs/10.1080/00103621003646063\#previ ew>. Acesso em: 24 ago. 2012.doi: 10.1080/ 00103621003646063.

PEREIRA, H.S. et al. Silicon sources for rice crop. Scientia Agrícola, v.16, p.522-528, 2004. Disponível em: <http://www. Scielo.br/pdf/sa/v61n5/21452.pdf>. Acesso em: 24 ago.2012.doi: 10.1590/S0103-9016200400 0500010.
PEREIRA, H.S. et al. Avaliação de fontes e de extratores de silício no solo. Pesquisa Agropecuária Brasileira, v.42, n.2, p.239-247, 2007. Disponível em: <http://www.scielo.br/pdf/pab/ v42n2/13.pdf $>$. Acesso em: 24 ago. 2012.doi: 10.1590/S0100204X2007000200013.

PEREIRA, H.S. et al. Reatividade de escórias silicatadas da indústria siderúrgica. Ciência e Agrotecnologia, v.34, n.2, p.382390, 2010. Disponível em: <http://www.scielo.br/pdf/cagro/ v34n2/16.pdf $>$. Acesso em: 14 maio, 2010.doi: 10.1590/S141370542010000200016 .

PRADO, R.M.; FERNANADES, F.M. Efeito da escória de siderurgia e calcário na disponibilidade de fósforo de um Latossolo Vermelho-Amarelo cultivado com cana-de-açúcar. Pesquisa Agropecuária Brasileira, v.36, n.9, p.1199-1204, 2001.Disponível em: <http://www.scielo.br/pdf/pab/v36n9/6480.pdf>. Acesso em: 16 jun. 2009. doi: 10.1590/S0100-204X2001000900014.

PRADO, R.M. et al. Uso agrícola da escória de siderurgia no Brasil - Estudos na cultura da cana-de-açúcar. Jaboticabal: Funep, 2001. 68p.

RAIJ, B. van. et al. Recomendação de adubação e calagem para o Estado de São Paulo. Campinas: IAC, 1996. 285p. (Boletim técnico, 100).

RAIJ, B. van. et al. Análise química para avaliação da fertilidade de solostropicais. Campinas: IAC, 2001. 285p.

RHEINHEIMER, D.S.; ANGHINONI, I. Distribuição do fósforo inorgânico em sistemas de manejo de solo. Pesquisa Agropecuária Brasileira, v.36, p.151-160, 2001. Disponível em: <http://www.scielo.br/pdf/pab/v36n1/4237.pdf>. Acesso em: 11 jan.2013. doi: 10.1590/S0100-204X2001000100019.

RODRIGUES, L.L. et al. Comparison of three soil test methods for estimating plant-available silicon. Communications in Soil Science and Plant Analysis, v.34, n.15-16, p.2059-2071, 2003. Disponível em: <http://www.tandfonline.com/doi/pdf/10.1081/ CSS-120024048>. Acesso em: 24 ago. 2012. doi: 10.1081/CSS120024048 . 